\title{
Desenvolvimento inicial de MUdAs de PLATHYMENLA FOLIOLOSA BENTH. SOB INFLUÊNCIA DE SOMBREAMENTO
}

\author{
Rubens Ribeiro da Silva ${ }^{1}$, Andrei Bocalon dos Anjos², Gilson Araújo de Freitas ${ }^{3 *}$, Aline Martins \\ Nogueira ${ }^{2}$, Álvaro José Gomes de Faria ${ }^{4}$
}

\author{
${ }^{1}$ Professor Adjunto de Solos e Nutrição de Plantas do curso de Agronomia da UFT - Campus Gurupi, CEP: 77402-970, Caixa Postal 66. Gurupi - \\ TO, Brasil. \\ ${ }^{2}$ Engenheiro (a) Florestal, Universidade Federal do Tocantins. \\ $3^{3 *}$ Engenheiro Agrônomo, Doutor, Bolsista do programa de pós-doutoramento/Pós-Graduação em Produção Vegetal - UFT, Câmpus de Gurupi. CEP: \\ 77402-970, Gurupi-TO. Caixa Postal 66, CEP: 77402-970. Gurupi - TO, Brasil. \\ ${ }^{4}$ Engenheiro agrônomo e Pós Graduando em Produção Vegetal. Universidade Federal do Tocantins (UFT) - Campos de Gurupi. \\ * Autor para correspondência: araujoagro@hotmail.com.
}

Recebido em 24 de maio de 2017. Aceito em 19 de maio de 2018. Publicado em 24 de julho de 2018.

REsumo - A adaptação de espécies nativas à condição de alto ou baixo nível de sombreamento é um fator importante na determinação da sobrevivência da uma espécie. Assim, o objetivo deste estudo foi verificar o desenvolvimento inicial de plantas de Plathymenia foliolosa Benth., sob influência do sombreamento. O experimento foi conduzido em delineamento de blocos casualizados, com três tratamentos (pleno sol, 50\% de luz e sombra natural) e 15 repetições, sendo cada repetição constituída por uma planta. Foi avaliado a massa seca das folhas, raízes, caule e total, a altura, diâmetro do colo, relação altura/diâmetro, relação massa seca da parte aérea/raiz e índice de qualidade de Dickson aos 60, 82, 103, 124 e 145 dias após a emergência das plantas. Foi observado que plantas expostas ao ambiente de sombra natural apresentaram menor desenvolvimento vegetativo do que em 50\% e pleno sol. A condição de 50\% de sombreamento pode ser recomendada para a formação de mudas, no entanto, essa prática também pode ser realizada a pleno sol.

Palavras-chave: Planta Nativa; Nílel De Luminosidade; Alocação De Biomassa.

\section{INITIAL DEVElopment of PLATHYMIA FOLIOLOSA BENTH. SEEDlings UNDER THE INFLUENCE OF SHADING}

Aвstract - The adaptation of native species to high or low level shading condition is an important factor in determining the survival of a species. The objective of this study was to verify the initial development of Plathymenia foliolosa Benth. plants, under the influence of shading. The experiment was conducted in a randomized complete block design with three treatments (full sun, 50\% light and natural shadow) and 15 repetitions, each repetition consisting of one plant. The dry mass of leaves, roots and stem was assessed, as well as height, stem diameter, height/diameter ratio, shoot/root dry mass ratio and Dickson quality index at 60, 82, 103, 124 and 145 days after seedlings emergence. It was observed that plants exposed to natural shade showed lower vegetation performance than in $50 \%$ and full sun. The $50 \%$ brightness can be recommended for the formation of seedlings, however, this practice can also be performed in full sun.

Keywords: Native Plant; Luminosity Level; Biomass Allocation.

Desarrollo inicial de plántulas de Plathymenla foliolos a Benth. bajo la influencia del sombreado

REsumen - La adaptación de las especies nativas a la condición de alto o bajo nivel de sombreado es un factor importante para la supervivencia de una especie. Así, el objetivo de este estudio fue evaluar el desarrollo inicial de las plantas de Plathymenia foliolosa Benth., bajo la influencia del sombreado. El ensayo se realizó en un diseño de bloques al azar con 
tres tratamientos (al pleno sol, el 50\% de luz y bajo sombra natural) y 15 repeticiones, cada repetición se constituyó de una planta. Se evaluaron la masa seca de las hojas, raíces, tallos y la masa total, la altura, el diámetro del cuello, relación altura/diámetro, relación masa seca de parte aérea/raíz y el índice de calidad de Dickson a los 60, 82, 103, 124 y 145 días después de la emergencia de las plántulas. Se observó que las plantas expuestas a la sombra natural tuvieron un crecimiento vegetativo menor que las plantas cultivadas bajo el 50\% de sombreado y menor que aquellas bajo el pleno sol. El 50\% de sombreado puede ser recomendado para la formación de plántulas, sin embargo, esta práctica también se puede realizar al pleno sol.

Palabras clave: Planta Nativa; Nivel De Luminosidad; Alocación De Biomasa.

\section{INTRODUÇÃO}

A espécie Plathymenia foliolosa Benth. pertence à família Fabaceae, subfamília Mimosoideae, sendo popularmente conhecida como vinhático, vinhático-da-mata, vinhático-rajado, vinhático-amarelo e pau-decandeia. É uma espécie típica de ocorrência no cerrado, heliófita, com dispersão irregular e descontínua (Lorenzi 2002; Warwick e Lewis 2003). A espécie possui porte arbóreo, com altura entre 15-30 m, tronco áspero e descamante e diâmetro altura do peito entre 40 a $70 \mathrm{~cm}$. A floração ocorre entre os meses de novembro e dezembro, junto com o surgimento de novas folhas. Os frutos iniciam a maturação no final de julho, estendendose até o final de agosto (Lorenzi 2002; Moraes Neto et al. 2001; Fonseca et al. 2013).

A árvore é ornamental, exuberante, útil para o paisagismo em geral (Lorenzi 2002). A espécie apresenta alto potencial para a produção madeireira e recuperação de áreas degradadas, justificando estudos visando à otimização das técnicas de produção de mudas da espécie (Souza e Lorenzi, 2008). No entanto, estudos revelam que o comportamento de algumas espécies apresenta diferenças significativas no seu crescimento quando em diferentes ambientes, demonstrando estratégias diferentes das plantas na utilização dos recursos disponíveis (Campos e Uchida 2002). Por isso, a importância de avaliar o comportamento de cada espécie frente a condições específicas de níveis de sombreamento, dentre outros.

A adaptação de uma espécie à quantidade de radiação solar caracteriza a mesma em um dos grupos ecológicos. As espécies pioneiras são dependentes de luz para o crescimento, as espécies clímax se desenvolvem melhor quando sombreadas, as secundárias iniciais e tardias se alocam nesse intermédio (Silva 2009).

Essa diferenciação de comportamento são estratégias de sobrevivência das plantas. Plantas que crescerem rapidamente quando sombreadas são adaptadas às condições de baixa intensidade luminosa em dosséis fechados (Moraes Neto et al. 2000). Plantas que crescem rapidamente em pleno sol tem crescimento acelerado e facilidade de adaptação a condições desfavoráveis (Souza et al. 2016)

A manipulação do sombreamento sobre espécies florestais em condições de viveiro pode fornecer dados importantes sobre a quantidade ideal de sombra para o melhor incremento da espécie estudada (Sabino et al. 2016). E características morfológicas e fisiológicas podem ser usadas para descrever o grau de tolerância das espécies sob condições de luminosidade (Duarte et al. 2015).

O conhecimento gerado em estudos fitossociológicos é importante para definir as espécies a serem utilizadas em projetos de recuperação de áreas florestais. Entretanto, pouco se conhece sobre o comportamento da espécie Plathymenia foliolosa em relação ao sombreamento. Esse tipo de informação é de suma importância para otimizar os modelos de regeneração a serem utilizados em projetos de recuperação de ambientes degradados. 
Diante disso, com o presente trabalho objetivo-se avaliar o desenvolvimento inicial de plantas de Plathymenia foliolosa Benth., em três níveis de sombreamento.

\section{MATERial e MÉtodos}

O estudo foi conduzido na área experimental da Universidade Federal de Tocantins (UFT), Campus Universitário de Gurupi, localizado na região sul do Estado do Tocantins, a $280 \mathrm{~m}$ de altitude, nas coordenadas $11^{\circ} 43^{\prime} 45^{\prime \prime}$ de latitude e $49^{\circ} 04^{\prime} 07^{\prime \prime}$ de longitude. O clima regional é do tipo B1wA'a' úmido com moderada deficiência hídrica. A temperatura média anual é de $29,5^{\circ} \mathrm{C}$, com precipitação anual média de $1804 \mathrm{~mm}$ (Koppen 1948). No período de avaliação a temperatura média foi de $25,8^{\circ} \mathrm{C}$ e precipitação pluviométrica média de 192,8 $\mathrm{mm}$.

As sementes de P. foliolosa foram coletadas na região de Gurupi-TO, em matrizes selecionadas quanto a sanidade vegetal, após terem caído pelo menos 30\% do volume de sementes produzidas. Posteriormente a coleta, as sementes foram levadas ao Laboratório de Sementes da UFT/CAUG em que passaram por um protocolo de assepsia, onde foram submetidas a um expurgo com o produto comercial Fermag ${ }^{\circledR}$ (fosfeto de magnésio), na recomendação de uma pastilha por um período de 48 horas.

Após descontaminação, as sementes foram colocadas para germinar em canteiro de areia lavada, localizado em viveiro com $50 \%$ da radiação solar. Após germinarem e atingirem um par de folhas, as plântulas foram transplantadas para sacos de polietileno com 0,28 $\mathrm{m}$ de altura e 0,15 $\mathrm{m}$ de diâmetro, contendo aproximadamente $2 \mathrm{dm}^{3}$ de substrato orgânico feito de terra preta, palha de arroz carbonizada e esterco bovino compostado, na proporção 2:1:1.

Foi realizada uma análise química do substrato, segundo metodologia da Embrapa (1997), possuindo $\mathrm{pH}(\mathrm{CaCl} 2)$ - 5,2; Matéria Orgânica - 4,7\%; Cálcio - 3,25 $\mathrm{cmol}_{\mathrm{c}} \mathrm{dm}^{-}$; Magnésio - 4,28 $\mathrm{cmol}_{\mathrm{c}} \mathrm{dm}^{-}$; Alumínio- 0,39 $\mathrm{cmol}_{\mathrm{c}} \mathrm{dm}^{-}$; Hidrogênio + Alumínio- 3,67 $\mathrm{cmol}_{\mathrm{c}} \mathrm{dm}^{-}$; Potássio- 39,1 $\mathrm{mg} \mathrm{kg}^{-1}$; Fósforo - 14,8 mg kg-1.

O experimento foi conduzido em delineamento de blocos casualizados, com três níveis de sombreamento, 15 repetições, sendo cada planta considerada uma repetição. Ao final dos 50 dias, após a emergência, as mudas de P. foliolosa foram submetidas aos níveis de sombreamento: pleno sol, 50\% de sombreamento e sombra natural. No tratamento com sombra natural, as mudas foram colocadas em uma área remanescente de vegetação nativa do cerrado Stricto senso, com 90\% de sombreamento medido com luxímetro. Enquanto o nível de 50\% de sombra foi obtido com tela de polietileno de coloração preta (sombrite). Durante as avaliações as mudas foram alocadas equidistantes a $0,4 \mathrm{~m}$.

Após dez dias de aclimatação, iniciaram-se as avaliações de altura e diâmetro do colo, sendo os dados coletados no intervalo de 21 dias, nos seguintes períodos de desenvolvimento: 60, 82, 103, 124 e 145 dias após emergência (DAE).

As características avaliadas foram: Altura da Planta (AP), Diâmetro de Colo (DC), Massa Seca de Folhas (MSF), Massa Seca do Caule (MSC), Massa Seca da Raiz (MSR), Massa Seca Total (MST), Relação Massa Seca da Parte Aérea/Massa Seca da Raiz (RPAR), Partição da Massa Seca (PMS), Relação Altura/Diâmetro (RAD) e Índice de Qualidade de Dickson (IQD).

Para avaliação de altura de planta e diâmetro do caule, foram avaliadas todas as mudas. Para as avaliações de massa seca das folhas, massa seca do caule, massa seca das raízes e massa seca total, considerou-se 33\% das 
plantas de cada tratamento, tomadas aleatoriamente mediante sorteio. A altura da planta foi considerada desde o colo até o ápice de cada planta, medida com régua graduada em centímetros ( $\mathrm{cm}$ ), e o diâmetro do colo medido com paquímetro graduado em milímetros $(\mathrm{mm})$, tomado a $1 \mathrm{~cm}$ do solo.

Para a determinação da massa seca as plantas foram separadas em folhas, caule e raízes. $\mathrm{Na}$ remoção do substrato aderido as raízes foram utilizados jatos brandos de água. Esta operação foi realizada sobre uma peneira de malha fina, de forma a evitar a perda de raízes. O material foi pesado separadamente em balança semianalítica e acondicionado em sacos de papel devidamente identificados, os quais foram colocados em estufa com circulação de ar forçada, à aproximadamente $70^{\circ} \mathrm{C}$, durante 72 horas (Moraes Neto et al. 2000).

O índice de qualidade de Dickson (IQD) foi determinado em função da altura da planta $(\mathrm{cm})$, do diâmetro do colo $(\mathrm{mm})$, do peso de matéria seca da parte aérea $(\mathrm{g})$ e do peso de matéria seca das raízes $(\mathrm{g})$, por meio da fórmula IQD = MST/[(AP/DC)+(MSPA/MSR)] (Dickson et al. 1960).

Os resultados foram submetidos à análise de variância, sendo as médias comparadas pelo teste de Tukey, ao nível de 5\% de probabilidade.

\section{RESUltados E Discussão}

Durante o período de avaliação das mudas de Plathymenia foliolosa Benth. no parâmetro altura, foi observado crescimento maior em plantas cultivadas em ambiente sob 50\% de sombreamento, com 41,34 cm de altura, enquanto plantas em pleno sol tiveram media de 29,18 cm e sombra natural 19,05 cm (Figura 1). Esse dado é corroborado pelo seu desenvolvimento natural da espécie no Cerrado (Lorenzi 2000). Resultado semelhante em ambiente de $50 \%$ de sombreamento foi encontrado com a espécie Dipteryx odorata (Uchida e Campos 2000) $e$ Senna macranthera (Almeida et al. 2005) que pertencem à mesma família da Platbymenia foliolosa.

Figura 1 - Altura das plantas de Plathymenia foliolosa sob três níveis de sombreamento. Médias seguidas pelas mesmas letras maiúsculas considerando DAE e letras minúsculas considerando os níveis de luz não diferem estatisticamente entre si, a $5 \%$ de probabilidade pelo teste tukey.

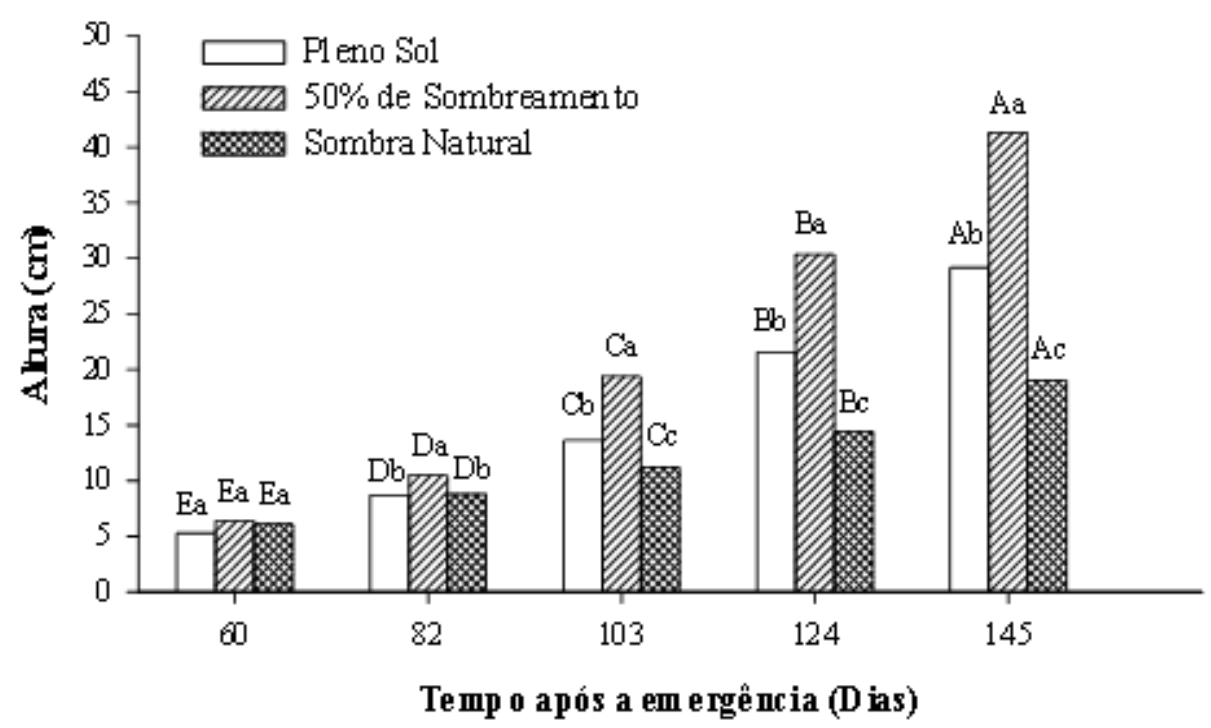


As plantas expostas em ambiente de sombra natural apresentaram menores alturas e um incremento pouco expressivo ao longo do tempo, provavelmente em função da falta de radiação, que influencia no fechamento de estômatos e na síntese de clorofila (Huang et al. 2011). Por outro lado, o excesso de radiação pode levar a muda a estresse fisiológico, impedindo seu desenvolvimento normal, o que pode explicar o fato de $50 \%$ ter tido melhor resultado (Moraes Neto et al. 2001).

Dentre as características morfológicas, a altura da planta fornece uma excelente estimativa do crescimento inicial no campo, sendo tecnicamente aceita como uma boa medida do potencial de desempenho das mudas, porém, pode ser influenciada por algumas práticas que são adotadas nos viveiros florestais. No entanto, trata-se de uma característica de fácil determinação, não sendo um método destrutivo, além de sua medição ser muito simples (Gomes et al. 2002; Gomes e Paiva 2011)

Quanto ao diâmetro do colo, foi observado que plantas cultivadas em ambientes de $50 \%$ de sombreamento apresentaram tendência a maior diâmetro, contudo a partir de 124 dias após a emergência (Figura 2).

Figura 2 - Diâmetro do colo das plantas de Plathymenia foliolosa sob três níveis de sombreamento. Médias seguidas pelas mesmas letras maiúsculas considerando DAE e letras minúsculas considerando os níveis de luz não diferem estatisticamente entre si, a $5 \%$ de probabilidade pelo teste tukey.

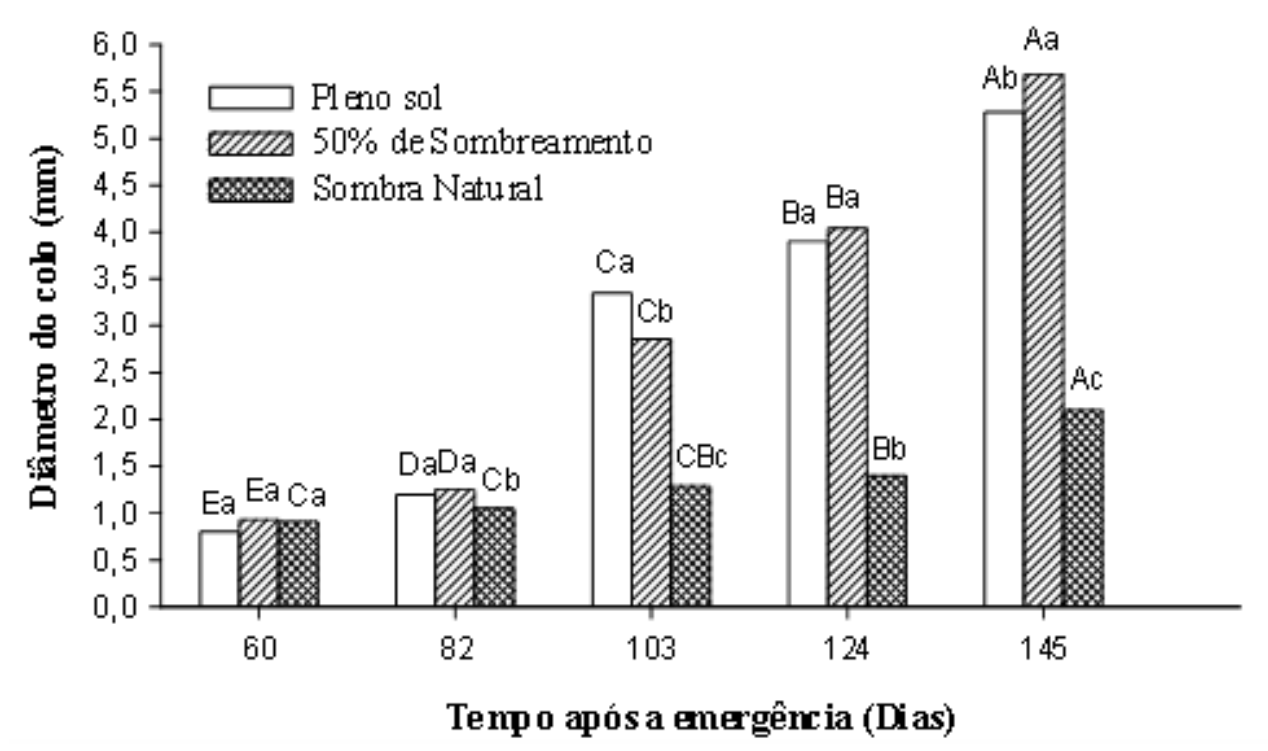

As plantas de Plathymenia foliolosa expostas ao ambiente de sombra natural apresentaram menor diâmetro ao longo do tempo provavelmente em função da falta de fotoassimilados disponíveis, pois a taxa fotossintética é muito baixa em relação às plantas cultivadas nos ambientes com maior disponibilidade de luz (Santos et al. 2014).

A medição do diâmetro do colo é um método não destrutivo e facilmente mensurável, sendo considerado por muitos pesquisadores como uma das mais importantes características para estimar a sobrevivência, logo após o plantio, de mudas de diferentes espécies florestais (Gomes e Paiva 2011).

Em relação ao acúmulo de massa seca, o sombreamento ocasionou diferença nas folhas, raízes e massa seca total das plantas de Plathymenia foliolosa Benth., em que foi observado que sob 50\% de sombra houve maior acúmulo de biomassa total, seguido da condição de pleno sol, diferindo estatisticamente das plantas sob sombra 
natural (Figura 3).

Figura 3 - Massa Seca da Folha (MSF), Massa Seca do Caule (MSC), Massa Seca de Raiz (MSR), Massa Seca Total (MST) e Relação Parte Aérea/Raiz (RPAR) das plantas de Plathymenia foliolosa sob três níveis de sombreamento aos 145 dias. Médias seguidas pelas mesmas letras, dentro de cada variável, não diferem estatisticamente entre si, a $5 \%$ de probabilidade pelo teste tukey.

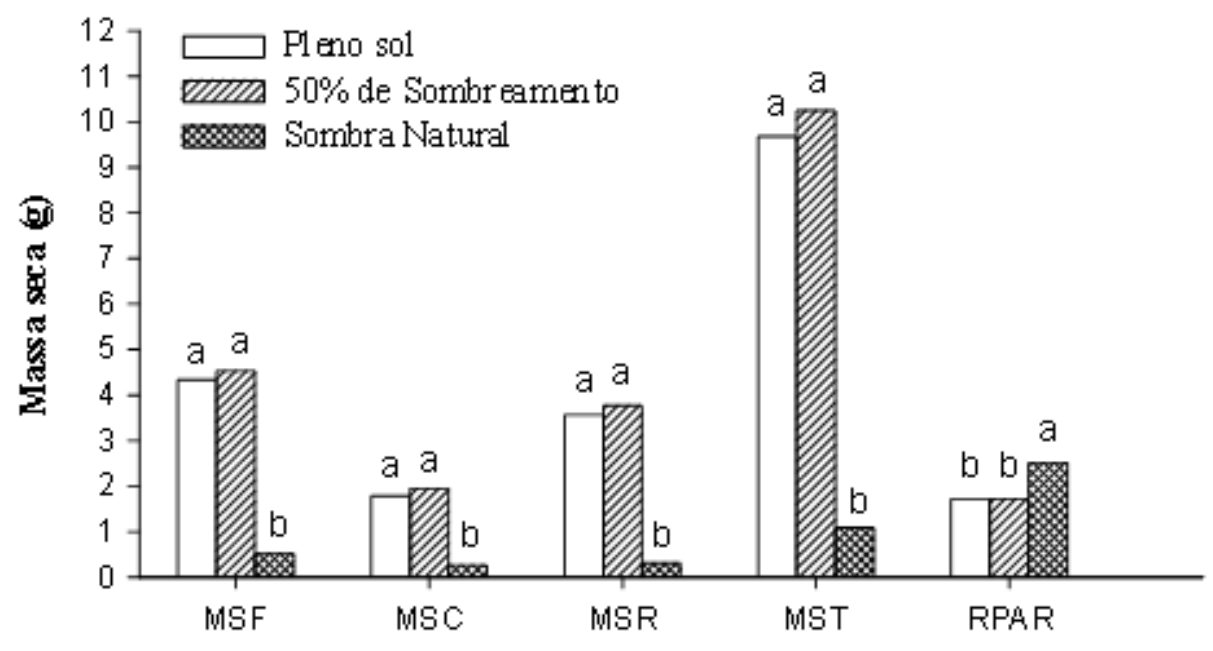

Abcação de biomassa

O menor valor de massa seca de folhas foi observado nas plantas em sombra natural. Plantas tendem a aumentar a fotossíntese sob maior disponibilidade de luz, crescendo também o teor de carboidratos nas folhas, que influenciou no incremento da massa seca em ambientes com maior luminosidade (Larcher 2000). As folhas são os principais órgãos fotossintetizantes e sua massa seca possui maior plasticidade frente às condições ambientais. As plantas sob maior sombreamento tendem a expandir o limbo foliar, aumentando a área de captação de luz, sem, no entanto, aumentar a massa seca (Huang et al. 2011).

Seu inapto desenvolvimento sob sombreamento é característica das plantas pioneiras e secundárias iniciais. Esse crescimento ineficaz da planta pode limitar a capacidade competitiva da espécie sob dossel fechado (Moreira e Carvalho 2013)

$\mathrm{Na}$ relação parte aérea/raiz (RPAR), sombra natural apresentou 2,52 g/g se diferenciando de 1,72 $\mathrm{g} / \mathrm{g}$ apresentados tanto em pleno sol como em $50 \%$ de sombreamento. O valor alto em sombra natural é interpretado como um desequilíbrio entre a planta, devido ao pouco desenvolvimento radicular decorrente à baixa atividade metabólica, reduzindo a produção de fotoassimilados que seriam translocados para as raízes. Esse baixo investimento em raízes e consequente aumento em área foliar pode ser notado na partição da massa seca.

A maior porcentagem de biomassa aérea foi encontrado nas plantas em sombra natural, observação essa, devido a intensificação da alocação de fotoassimilados para a parte aérea, sendo uma forma de compensar o maior sombreamento (Silva et al. 2009).

As mudas que receberam mais radiação tiveram maior porcentagem radicular, isso é um mecanismo que permite a planta realizar maior absorção de água e nutrientes para suportar altas taxas de fotossíntese e transpiração sob alta intensidade de luz. Plantas com esse tipo de estratégia devem ser usadas nos grupos 
iniciais em áreas sob processo de recuperação de áreas degradas, pois garantem o desenvolvimento inicial e condicionam a continuidade dos estágios sucessionais (Carvalho et al. 2006).

Outro parâmetro importante é a relação altura/diâmetro (RAD), que indica plantas menos resistentes no campo às condições impostas pelo ambiente. Mudas com menores valores representaram maior qualidade, uma vez que se espera um equilíbrio no desenvolvimento (Uchida e Campos 2000). A maior relação A/D foi obtida no nível de sombreamento de sombra natural, a partir dos 103 dias após a emergência (Figura 4).

Figura 4 - Relação Altura/Diâmetro das plantas de Plathymenia foliolosa sob três níveis de sombreamento. Médias seguidas pelas mesmas letras maiúsculas considerando DAE e letras minúsculas considerando os níveis de luz não diferem estatisticamente entre si, a $5 \%$ de probabilidade pelo teste tukey.

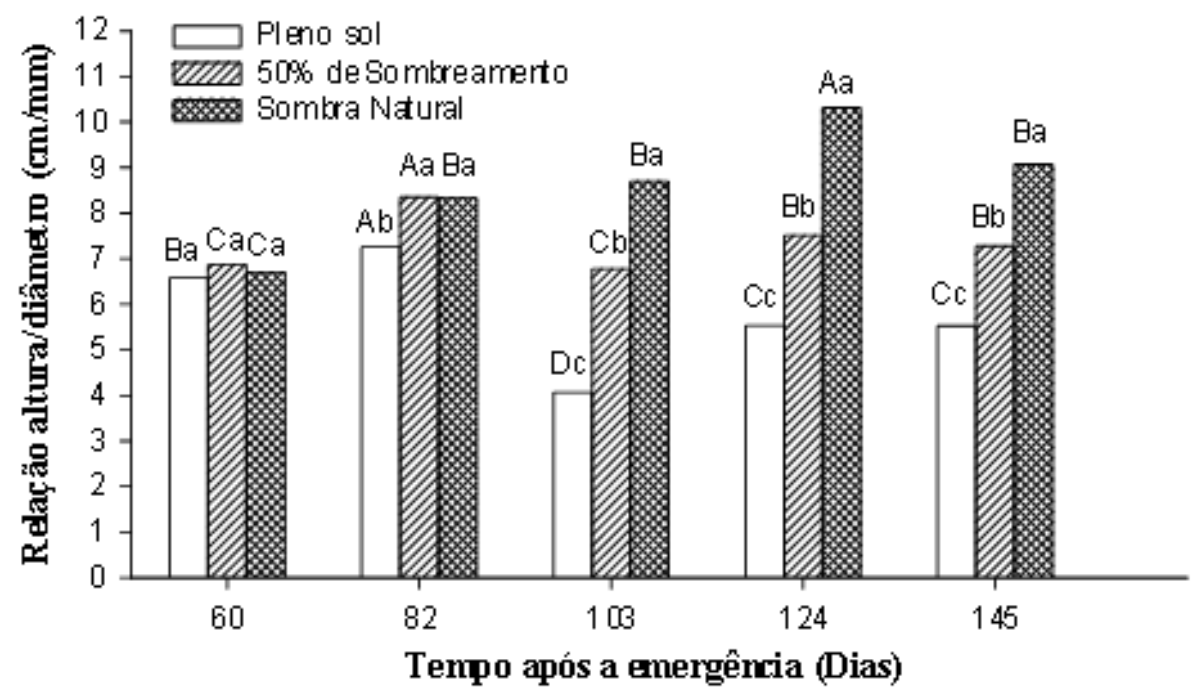

No tratamento a pleno sol foi observado durante o período de avaliação, que a partir dos 82 dias após a emergência, houve um decréscimo na relação altura/diâmetro. Essa é uma característica importante pois valores menores nesse parâmetro representa um maior equilíbrio entre as partes da planta, posteriormente, mais robusta será a planta (Aguiar et al. 2011).

Esses resultados podem ser comparados com mudas estioladas, que apresentam um crescimento em altura alto em relação ao seu diâmetro do colo, gerando uma muda de baixa qualidade, e na Relação Altura/Diâmetro apresentaria valores elevados. Menores valores na relação altura/diâmetro se relacionam diretamente com maior sobrevivência das mudas no campo (Silveira 2004).

Já o índice de qualidade de Dickson é importante indicador da qualidade das mudas (Figura 5). Quanto maior o valor desse índice, mais vigorosa será a planta (Gomes e Paiva 2011), pois no seu cálculo são considerados a robustez e o equilíbrio da distribuição da biomassa na planta.

O maior valor no índice de qualidade de Dickson foi 1,34 obtidas em plantas de P. foliolosa Benth. submetidas a $50 \%$ de sombreamento, seguido do tratamento pleno sol $(1,14)$. Plantas submetidas a sombra natural tiveram 0,085 de IQD, devido menor diâmetro do colo, baixa massa seca e alta relação altura/diâmetro.

A exigência de baixo sombreamento viabiliza a utilização da $P$. folilosa como espécie secundária inicial em áreas degradadas sob processo de recuperação da vegetação. As espécies do estágio sucessional secundário inicial 
ocorrem em clareiras pequenas, bordas de clareiras grandes, bordas de floresta ou subosque não densamente sombreado, sendo essa a necessidade de luminosidade requerida pela P. foliolosa, ou seja, condição próxima a $50 \%$ de luminosidade.

Figura 5 - Índice de Qualidade de Dickson (IQD) dos tratamento de Platbymenia foliolosa sob três níveis de sombreamento. Médias seguidas pelas mesmas letras, não diferem estatisticamente entre si, a 5\% de probabilidade pelo Teste Tukey.

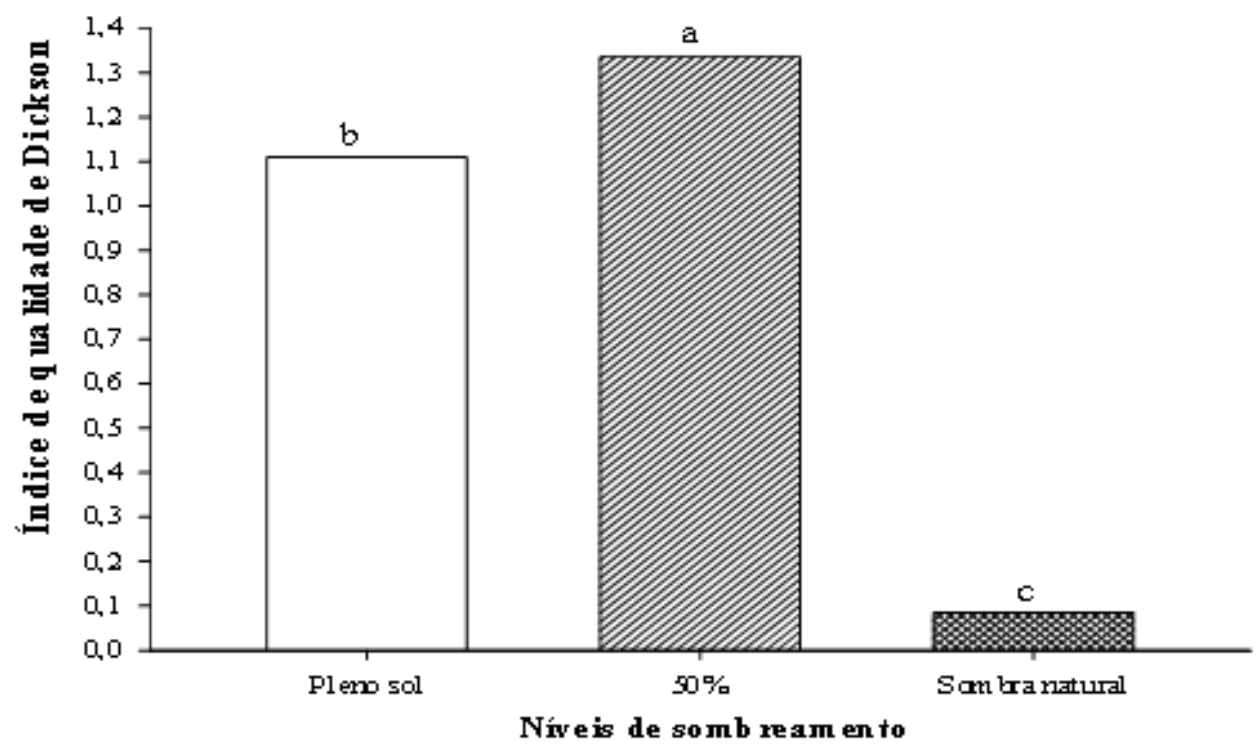

Estes resultados estão de acordo com os trabalhos sobre a $P$. foliolosa Benth., que mostram necessitar a espécie de um certo grau de luminosidade durante seu crescimento inicial (Neubert 2014).

\section{Conclusão}

Mudas de Plathymenia foliolosa Benth. devem ser produzidas sob condições de 50\% de sombreamento devido o melhor desempenho em altura, diâmetro, massa seca, alocação de biomassa e índice de qualidade de Dickson.

\section{REFERÊNCIAS}

Aguiar FF, Kanashiro S, Tavares AR, Nascimento TDR e Rocco FM 2011.Crescimento de mudas de pau-brasil (caesalpinia echinata lam.), submetidas a cinco níveis de sombreamento. Ceres, 58 (6): 729-734.

Almeida SMZ, Soares AM, Castro EM, Vieira CV e Gajego EB. 2005. Alterações morfológicas e alocação de biomassa em plantas jovens de espécies florestais sob diferentes condições de sombreamento. Ciência Rural, 35(1): 62-68.

Campos AAC e Uchida T. 2002. Influência do sombreamento no crescimento de mudas de três espécies amazônicas. Pesquisa agropecuária brasileira, 37 (3): 281-288. 
Carvalho NOS, Pelacani CRR, Manuela OS e Crepaldi IC. 2006. Crescimento inicial de plantas de licuri (Syagrus coronata (Mart.) Becc.) em diferentes níveis de luminosidade. Revista Árvore, 30(3): 351-357

Dickson A, Leaf AL e Hosner JF. 1960. Quality appraisal of white spruce e white pine seedling stock in nurseries. Forest chronicle, 36: 10-13.

Duarte ML, Paiva HN, Alves MO, Freitas AF, Maia FF e Goulart LML. 2015. Crescimento e qualidade de mudas de vinhático (Plathymenia foliolosa benth.) em resposta à adubação com potássio e enxofre. Ciência florestal, 25 (1): 221-229.

Fonseca MDS, Freitas TAS, Mendonça AVR, Souza LS e Abdalla SD. 2013. Morfometria de sementes e plântulas e verificação da dormência da espécie Plathymenia foliolosa benth. Comunicata scientiae, 4(4): 368-376.

Gomes JM, Couto L, Leite HG , Xavier A e Garcia SLR. 2002. Parâmetros morfológicos na avaliação da qualidade de mudas de Eucalyptus grandis. Revista árvore, 26(6): 655-664.

Gomes JM, Paiva HP. Viveiros florestais (propagação sexuada). 3. Ed. Viçosa: UFV, 116 p, 2011.

Huang D, Wu L, Chen JR e Dong L. 2011. Morphological plasticity, photosynthesis e chlorophyll fluorescence of Atbyrium pachyphlebium at different shade levels. Photosynthetica, 49: 611-618.

Koppen W. 1948. Climatologia: con un estudio de los climas de la tierra. Fondo de cultura econômica, México, $479 \mathrm{p}$.

Larcher, W. 2000. Ecofisiologia vegetal. São Carlos: Rima, 531 p.

Lorenzi, H. 2000. Árvores brasileiras: manual de identificação e cultivo de plantas arbóreas nativas do brasil. $3^{\circ}$ edição. Nova Odessa, São Paulo, 368 p.

Lorenzi, H. 2002. Árvores brasileiras: manual de identificação e cultivo de plantas arbóreas nativas do brasil. $2^{\circ}$ edição. Nova Odessa: Instituto Plantarum, 382 p.

Moraes Neto SP, Gonçalves JLM, Takaki M e Cenci S. 2000. Crescimento de mudas de algumas espécies arbóreas que ocorrem na mata atlântica, em função do nível de luminosidade. Revista Árvore, 24: 35-45.

Moraes Neto SP, Gonçalves JLM e Takaki. 2001. M. Produção de mudas de seis espécies arbóreas, que ocorrem nos domínios da floresta atlântica, com diferentes substratos e níveis de luminosidade. Revista Árvore, 25(3): 277-287.

Moreira B, Carvalho FA. 2013. A comunidade arbórea de um fragmento urbano de floresta atlântica após 40 anos de sucessão secundária (Juiz de Fora, Minas Gerais). Biotemas, 26(2): 59-70.

Neubert VF. 2014. Propagação vegetativa do vinhático (plathymenia foliolosa benth) por miniestaquia, Viçosa: UFV, 48 p.

Sabino M, Korpan C, Ferneda BG e Silva AC. Crescimento de mudas de ipê em diferentes telas de sombreamento. Nativa, 4(2): 61-65. 
Santos GM, Paiva JCQC, Scalon SPQ e Mussury RM. 2014. Avaliação da intensidade luminosa no desenvolvimento inicial de espécies frutíferas nativas do cerrado. Acta Biológica Catarinense, 1(1): 5-14.

Silva RR, Freitas GA, Melo AV, Pietralonga AG, Aguiar RWS, Pelúzio JM e Nascimento IR. 2009. Potencial de desenvolvimento inicial da aspidosperma polyneuron müll em projetos de recuperação de área degradada na região sudeste da amazônia legal. Pesquisa Aplicada \& Agrotecnologia, 2(1).

Silveira SV, Souza PVD e Koller OC. 2004. Propagação vegetativa de abacateiro por estaquia. Revista Brasileira de Fruticultura, 26(1): 191-192

Souza JB, Rios AER, Nascimento EM, Fonseca GO, Macedo JLA, Vianin KN e Almeida TLN. 2016. Recuperação da área degradada de planejamento ambiental do parque gentil diniz - contagem/mg, E-xacta, 9(1): 63-78.

Souza VC e Lorenzi H. 2008. Botânica sistemática - guia ilustrado para a identificação das famílias de fanerógamas nativas e exóticas no Brasil, baseado em APG II Nova Odessa: Plantarum, São Paulo, 728p.

Uchida T e Campos MAA. 2000. Influência do sombreamento no desenvolvimento de mudas de cumaru (Dipteryx odorata (aulb.) Wild. Fabaceae), cultivadas em viveiro. Acta Amazonica, 30(1): 107-114.

Warwick MC e Lewis GP. 2003. Revision of Plathimenia (leguminosae- mimosoideae). Edinburgh Journal of Botany, 60(2): 111 - 119. 